\title{
De frente para o crime: a política externa brasileira diante dos crimes contra a humanidade no pós-guerra fria: da intervenção humanitária à ampliação do Conselho de Segurança
}

\author{
Wellington Pereira Carneiro'
}

\section{Resumo}

O presente artigo descreve e analiza as posições da diplomacia brasileira frente às grandes tragédias humanitárias que afetaram o mundo no pós guerra fria. Neste sentido se concentra no conteúdo das partipações brasileiras no Conselho de Segurança das Nações Unidas durante este período historico que presenciou grandes desafios para o sistema de segurança como as crises da Iugoslavia, Timor Leste, Kosovo e mais recentemente a ousada decisão sobre Darfur en 2005. Sem pretender una análise completa uma vez que se trata de problemas ainda em pleno debate na arena internacional o artigo dita algumas pautas para futura acompanhamento analitico. Conclui-se que o Brasil vem avançando em relação a uma politica para o sistema de segurança em geral mas lhe falta uma resposta aos graves conflitos étnico-politicos que proliferaram no pós guerra fria, que de resto a comunidade interancional como um todo não dispõe.

Palavras-chave: Intervenção humanitária. Conselho de Segurança

\section{Introdução}

O período pós-Guerra Fria tem sido de grande instabilidade na história do sistema de segurança do Pós-Segunda Guerra Mundial. A explosão dos conflitos étnicos, as instabilidades regionais e recrudescimento dos nacionalismos

\footnotetext{
${ }^{1}$ Wellington Pereira Carneiro, Mestre em Direito Internacional dos Direitos Humanos pela Universidade de Oxford, Reino Unido, e em Direito Internacional Público pela Universidade "Drujby Narodov", Moscou; Doutorando em Relações Internacionais pela UnB.
} 
e fundamentalismos e os fenômenos políticos pelos quais o Brasil tem passado relativamente incólume têm apresentado constantes desafios.

O sistema de segurança internacional tem sido acusado de obsoleto, irrelevante e ineficiente ao mostrar limitações logo depois da Guerra Fria (Somália 1993) e estarrecer o mundo com rotundas falências durante o Genocídio de Ruanda, em 1994 e na Iugoslávia (Srebrenica) em julho de 1995.

O Brasil tem participado ativamente do sistema de segurança coletiva inaugurado após a Segunda Guerra Mundial. No entanto, o final da Guerra Fria foi um dos períodos de mudança histórica que menos produziu mudanças institucionais e rearranjos da ordem internacional. Podemos citar a OMC, o Tribunal Penal Internacional e o Conselho de Direitos Humanos como importantes ajustes institucionais. No entanto, no marco do sistema de segurança coletiva, pouco mudou. $\mathrm{O}$ mesmo Conselho de Segurança, fundado sobre uma ordem bipolar e com a participação de 51 países independentes em 1945, permanece como o órgão máximo para assegurar a paz e a segurança, num mundo semi-unipolar com 192 países.

O Brasil, principalmente após o final da Guerra Fria, tem advogado pela ampliação do Conselho e participado do processo de reconfiguração das missões de paz e também participou ativamente do movimento do grupo de países chamados "like minded" que garantiu a aprovação do Estatuto de Roma e, portanto, a instalação do Tribunal Penal Internacional (TPI) que foi uma mudança marcante na história da justiça internacional, longamente adiada. O Brasil investe na institucionalização e no fortalecimento do direito internacional.

Consequentemente, nos dez anos posteriores, um intenso período de reflexão se estabeleceu. As propostas de reforma foram aparecendo até a aprovação do conceito do "dever de proteger" na Conferência Mundial de 2005, conceito ao qual o Brasil se opõe discretamente, mais se aproximando da reserva que da oposição aberta. Por outro lado, a política externa brasileira tem apostado em respostas multilaterais de cunho estrutural como o TPI, as novas operações de paz e a ampliação do Conselho de Segurança. No entanto, tem produzido pouca ou nenhuma doutrina, e no campo das iniciativas práticas a MINUSTAH, comandada pelo Brasil, tem apresentado resultados pouco animadores. No que tange à proposta de ampliação do Conselho, parcialmente 
tem prevalecido a reforma doutrinária, sem mudanças estruturais, capitaneada pelo Canadá e não a reforma estrutural reivindicada pelo Brasil, Índia, Alemanha e Japão.

Todos esses debates e definições aconteceram nos dez anos marcados pela década posterior aos grandes genocídios do Pós-Guerra Fria, entre 1995 e 2005. Apesar da reforma doutrinária entre 2003 e 2005, justamente outro genocídio se configura em Darfur.

2 Contexto histórico: direitos humanos e segurança internacional

O Conselho de Segurança vem incorporando a dimensão dos direitos humanos progressivamente, com uma breve desaceleração a partir de 2001, quando dos atentados às torres gêmeas, quando a luta contra o terrorismo passou a dominar sua agenda.

O sistema foi constituído com seu centro inequívoco na segurança dos Estados nacionais, sem qualquer referência aos seres humanos. No marco da Carta de São Francisco, o tripé, desenvolvimento, direitos humanos e segurança aparecem pouco relacionados e a segurança surge praticamente divorciada dos demais componentes.

As primeiras tímidas aparições da preocupação com as pessoas aparecem nas resoluções que lamentam as crises humanitárias provocadas pela expulsão dos palestinos na Guerra de Independência de Israel em 1948; no conflito entre Índia e Paquistão e na Guerra da Coréia em 1950, em que a crise humanitária aparece como elemento subjacente no marco de suas medidas puramente securitárias.

A Resolução 134 sobre o massacre de Shapeville, ocorrido em 1960 na África do Sul, constitui um marco na incorporação da dimensão humana da segurança internacional. O Conselho muda seu enfoque dos problemas puramente internos aos Estados e declara que a situação na África do Sul, ou seja, o do tratamento da população negra poderia afetar a paz e a segurança internacionais. (ANJOS, 2007).

Todas as ações do Conselho tomadas posteriormente, inclusive em relação à ocupação da Namíbia e a independência da Rodésia do Sul, vêm em consonância com esse passo inicial até a votação de sanções econômicas e o banimento da África do Sul da Assembléia Geral ainda que jamais tenha sido expulsa da ONU. 
A Resolução 688 sobre a situação do Iraque votada em 5 de abril de 1991 foi muito mais categórica, ao afirmar que a violação sistemática de direitos humanos ameaçava efetivamente a paz e a segurança internacionais. A atroz repressão do governo Sadam Hussein às rebeliões xiitas e curdas motivou a primeira medida militar de proteção de populações civis determinada pelo Conselho; o estabelecimento da zona de exclusão aérea "no fly zone" para a proteção das populações curdas refugiadas em regiões inóspitas nas montanhas entre o Curdistão Turco e o Iraquiano. A partir do final da Guerra Fria e das crises que se seguiram o Conselho viveu uma época de relevância da preocupação com os direitos humanos, apesar dos fracassos nesse sentido, os que justamente comprometeram a legitimidade do sistema de segurança coletivo.

As resoluções do Conselho sobre as crises da Croácia, Bósnia-Herzegovina, Macedônia e Kossovo refletem uma crescente preocupação pelo destino das pessoas encurraladas nas áreas de conflito. As resoluções sobre Ruanda, Serra Leoa, Libéria, Haiti e Timor Leste, todas nos anos noventa, apresentam este elemento que se tornou um componente destacado das preocupações do Conselho de Segurança. Por outro lado, o estabelecimento de dois tribunais penais ad hoc e finalmente a mudança do mandato das missões de paz a partir da MONUC na República Democrática do Congo, incorporando também o mandato para proteger populações civis, e licença para combater, se necessário, tenta dar uma resposta aos questionamentos sofridos pela inércia fatal que possibilitou o genocídio em Ruanda.

A prevalência dos direitos humanos como norma de conduta dos Estados das mais diversas composições tem alimentado o debate sobre a interpenetração desta última fronteira que constitui o sistema de segurança coletivo. Apesar dos retrocessos dos anos de combate ao terrorismo, que trouxeram de volta aberrações reputadas erradicadas no contexto da segurança internacional, como a utilização sistemática da tortura e de detenções arbitrárias na prática dos "extraordinary renditions", e dos campos de prisioneiros em Guantânamo, não enfraqueceram a tendência geral e chamaram a atenção para a necessidade de um enfoque da segurança internacional que considere os direitos humanos como um componente fundamental.

A extraordinária e surpreendente ratificação do Tratado de Roma que constituiu o Tribunal Penal Internacional serve como o exemplo mais acabado de 
que a via da legalidade no uso da força vem ganhando terreno no cenário das relações internacionais. Por outro lado, as intervenções não sancionadas pelo conselho em Kossovo e Iraque demonstram a tendência contrária.

O Tribunal Penal Internacional está jogando sua carta de vida ou morte em Darfur, e os efeitos de sua intervenção em um conflito em curso determinará sua relevância no futuro próximo. Sintomaticamente, todos os países que advogam pela ampliação do Conselho ratificaram o tratado de Roma. Entre os membros do Conselho de Segurança apenas Inglaterra e França integram o Tratado. Esse fato igualmente demonstra a busca por uma maior legitimidade, legalidade e transparência no sistema de segurança coletivo.

O arranjo de 1945 é visto como artificial, elitista e vazio no sentido de que a atual configuração do Conselho de Segurança não mais reflete a composição do poder político e militar no mundo. No entanto, a ilusão da unipolaridade ainda não sucumbiu à realidade de forma histórica e incontestável, devido à superioridade inconteste dos Estados Unidos ainda que claramente superestimada. O novo papel dos direitos humanos no mundo não permite que se continue a ver a segurança sob as lentes de um mundo que não existe mais.

\section{Participações do Brasil no Conselho de Segurança}

\subsection{Biênio 1993 - 1994}

Em 1993, o Conselho de Segurança votou 92 resoluções, tendo sido esse um ano particularmente instável e preocupante do ponto de vista da segurança internacional. A eclosão do conflito na ex-Iugoslávia trazia a guerra de volta à Europa. Já em janeiro, o Conselho é confrontado com as violações massivas de direitos humanos e violações do direito internacional humanitário, inclusive com ataques a áreas protegidas pela missão de paz UNPROFOR (Resolução 802) por parte de forças croatas. Essa Resolução que se soma a outras seis tomadas em virtude de violações massivas do direito internacional humanitário leva a adoção de uma resolução marco pelo seu pioneirismo. A Resolução 808 de 22 de fevereiro cria o primeiro Tribunal Penal Internacional desde Nuremberg criado após a Segunda Guerra Mundial: o Tribunal Penal para a ex-Iugoslávia. O Brasil acompanhou o voto de todos os quinze membros que aprovaram por unanimidade este passo. 
Outro evento relevante para o Brasil foi a Resolução 804 na qual o Conselho condena expressamente a UNITA de Angola. Em 1992, um acordo permite a realização de eleições que foram vencidas pelo partido no governo MPLA. A UNITA não aceita o resultado e tenta tomar Luanda, mas é rechaçada depois de três dias de violentos combates. A parceria do Brasil com Angola, grande comprador de óleo cru, e seu caráter de país de língua portuguesa tornavam a estabilidade de Angola importante para o Brasil. O Brasil durante toda a década de noventa e, particularmente, a partir de 1993, recebeu centenas de refugiados angolanos a cada ano e acompanhou o voto unânime dos membros do Conselho. Todavia, no ano de 1993, mil pessoas morreram todos os dias no conflito angolano.

A Resolução 814 de 1993 reflete essa fase controversa, na qual o Brasil teve a oportunidade de participar e, no começo dos anos noventa, o Conselho de Segurança lançou uma série de iniciativas de intervenção bastante ambiciosas, gozando do amplo consenso entre seus membros. O começo da nova ordem mundial no Chifre da África debutou com uma missão para o restabelecimento da paz na Somália entre 1992 e 1993 que fracassou rotundamente, provocando um recuo significativo em todas as propostas de intervenção para o restabelecimento da paz. No ano seguinte, justamente quando uma intervenção mais corajosa e efetiva era esperada diante da mais grave e mais evidente ameaça de conflito atroz em Ruanda, um perigoso estado de letargia prevaleceu.

O ano de 1994 assistiu à implementação dos acordos de paz em Moçambique, o fim do regime de Apartheid na África do Sul, as crises da Abkhazia, Geórgia, Haiti com a queda de Aristide, Somália e a condenação do cerco de Sarajevo na Guerra da Bósnia (Res. 900), que o Brasil apoiou. No entanto, nenhuma crise foi tão contundente como a crise de Ruanda.

\subsubsection{Ruanda}

Em Ruanda, a missão de paz com um mandato limitado para observar o cumprimento dos acordos de Arusha foi estabelecida pela Resolução 812 de março de 1993, uma vez mais votada por unanimidade. Na ante-sala do desastre, dois fatos importantíssimos aconteceram. Foi absolutamente provada a relativa efetividade dos sistemas de alerta antecipado, ou seja, a possibilidade de antever com 
anterioridade razoável o risco de um fenômeno tão complexo como o genocídio. O relator da ONU para execuções arbitrárias, sumárias ou extrajudiciais (UNITED NATIONS, 1993), B.W. Ndiaye visitou Ruanda entre os dias oito e dezessete de abril de 1993, onde ele descreveu os massacres de pessoas da etnia Tutsi como genocídio, e chamou a tomar medidas a respeito em um informe apresentado aos organismos de direitos humanos da $\mathrm{ONU}$ em agosto do mesmo ano. Igualmente em janeiro de 1994, o comandante da operação de observação dos acordos de paz em Ruanda, UNAMIR, General Romeo Dalaire, obteve evidências de que uma ampla operação de extermínio da minoria Tutsi estava sendo planejada nas mais altas esferas do poder e do governo, com extremistas hutus espalhados por vários setores da vida social, participando ativamente do plano, desde o exército até círculos empresariais (DALAIRE, 2003, p. 143).

A Resolução 909, votada no dia 05 (na véspera do início do genocídio), já dava mostras de que a UNAMIR enfrentava problemas de financiamento e que os resultados eram parcos. No auge do genocídio, no dia 21 de abril, o Conselho reconhece a matança de centenas de civis e ajusta o mandato da UNAMIR para proteger a população civil que buscasse refúgio ao lado de suas tropas, o que foi apoiado pelo Brasil. No entanto, é somente com a Resolução 918 que o Conselho, estendendo ainda o mandato da UNAMIR para proteger as operações de socorro humanitário, autoriza a extensão para 5.500 homens e impõe um embargo de armas. Essa Resolução destacou-se por descrever a definição do crime de genocídio sem, no entanto, pronunciá-lo o que chamaria a responsabilidade internacional de intervir.

A Resolução 929 de 22 de junho de 1994 estabeleceu a Operação Turquoise, liderada pela França, que deveria proteger as operações de socorro humanitário e, igualmente, estendeu o mandato da UNAMIR. No entanto, o genocídio estava praticamente completo e, alguns dias depois, a FPR tomaria Kigali, colocando um fim ao genocídio e dando lugar ao êxodo forçado de 1,5 milhão de pessoas. As Resoluções comentadas contaram sempre com um alto grau de consenso, sendo a maioria votada por unanimidade. No entanto, seu fracasso foi rotundo. O Conselho, com a participação do Brasil, em novembro, já afirmando que houvera genocídio, estabeleceu o Tribunal Penal para Ruanda, já que a punição aos culpados era o único que restava e que seria possível fazer. 


\subsection{Biênio 1998 - 1999}

A Guerra na Bósnia tinha chegado ao fim logo depois dos acordos de Dayton. No entanto, a crise no Kosovo que esteve na raiz dos conflitos de toda a exIugoslávia se reacende. A comemoração dos 600 anos da batalha de Kosovo Pole, em 1989, foi o palco onde Slobodan Milosevic fez o seu chamado à guerra étnica (BOZIC-ROBERTSON, 2004). Em março de 1998, o embaixador brasileiro Henrique Valle, diante da nova onda de instabilidade nos Bálcãs, alertava o conselho de que a comunidade internacional deveria agir imediatamente para a pacificação do Kosovo, evitando os erros do passado (VALLE, 1998). A proposta brasileira se centrava na diplomacia preventiva, ou seja, criar por meio da intervenção multilateral as condições para o diálogo entre as partes em conflito. O Brasil levantou importantes questionamentos a respeito da possibilidade de aplicação de sanções sob o capítulo VII quando se tratava de um conflito interno. No entanto, ao mesmo tempo em que favoreceu a imposição de sanções contra a Sérvia, pediu o respeito pela sua integridade territorial e soberania, alertando para a tendência de tomar de forma relativa o princípio de não-intervenção. Infelizmente, os temores levantados pelo Brasil foram justificados.

Em 1999, a oposição da Rússia e a ameaça de veto no Conselho de Segurança se combinaram com a longa história de violência nos Bálcãs e levaram a primeira grande ruptura da legalidade internacional, na intervenção da OTAN na ex-Iugoslávia. O sistema de segurança coletivo foi confrontado com sua primeira grande falência estrutural.

Em junho de 1999, o Brasil expressava seu desconforto numa cuidadosa declaração que pretendia questionar a ruptura da legalidade internacional, mesmo diante dos reiterados massacres em Kosovo.

Ao mesmo tempo e, independente de considerações morais invocadas para estas ações, com as quais nos identificamos plenamente; problemáticos precedentes foram estabelecidos no recurso à forca militar sem autorização do Conselho de Segurança (FONSECA JR, 1999b, tradução nossa).

O Brasil, nessa discussão, introduziu o dilema sem solução que persegue o sistema de segurança desde Ruanda; o que fazer, diante do genocídio e dos crimes contra a humanidade? Nesse dilema se combinam o sistema baseado 
sobre os princípios de não intervenção nos assuntos internos, soberania nacional e integridade territorial, o uso da força limitado a situações específicas, e o fato de que o sistema se neutraliza e paralisa a si mesmo, com instituto do veto no Conselho de Segurança. Nesse sentido, o Brasil se alinhou com o Secretário Geral em uma grande divergência com a Europa e os Estados Unidos;

É possível esperar, juntamente com o Senhor Secretário Geral Kofi Annan, que, no futuro, os países não tenham que escolher entre a inação e o genocídio, a intervenção e a divisão do Conselho (FONSECA JR, 1999b, tradução nossa).

Igualmente as declarações do Brasil tentavam contemporizar e buscar um consenso em torno de um novo paradigma sem, no entanto, propor uma nova doutrina de segurança coletiva. O Brasil preferiu confiar no retorno à legalidade internacional no manejo da crise, e clamar para que o próprio Conselho buscasse um novo consenso multilateral para que soluções para os sérios problemas que estavam afetando a segurança mundial pudessem surgir gradualmente.

No caso do Timor Leste, o debate adquiriu um tom muito mais consensual e a participação do Brasil no Conselho foi mais ofensiva tentando assumir um papel de maior protagonismo, participando com um significativo contingente na missão de paz e apoiando as iniciativas mediadoras do Primeiro Ministro de Portugal, Antonio Guterres, para a efetiva independência do Timor Leste, num vácuo do pós-guerra Fria que permitiu esse evento histórico. Cabe também notar que o Timor Leste foi o grande salto na carreira de Sergio Vieira de Melo, que foi nomeado chefe da missão da ONU no Timor para a reconstrução e pacificação do país, que mantinha uma estreita relação com as autoridades brasileiras, presentes no Timor Leste.

Nesse debate, o Brasil se destacou pelo seu apoio à independência do Timor, a pacificação do país por meio de uma missão de paz liderada pela Austrália, o desarmamento dos paramilitares indonésios e timorenses e o retorno dos refugiados, assim como a reconstrução nacional.

A língua portuguesa tinha sido duramente reprimida, assim como o catolicismo. A reconstrução introduziu o elemento de identificação cultural do Timor Leste que passou a integrar a comunidade de países de língua portuguesa, ainda que grande parte de sua população já não falasse o português, mas um papiamento chamado Tetum, que mistura línguas nativas com elementos de português. 
No entanto, o debate mais importante que, sintetizando os desafios dos anos noventa em matéria de segurança coletiva, galvanizou o caminho para um sistema voltado para a segurança humana, foi o debate sobre a proteção da população civil durante os conflitos armados.

Nesse debate, a posição do Brasil foi igualmente crítica, porém com poucas propostas inovadoras. A diplomacia brasileira teve a coragem e a clareza para reconhecer o aumento extraordinário das vítimas civis dos conflitos armados no final do século XX, criticou as sanções que, ainda que não as mencionasse expressamente, estavam lastreadas no tremendo fracasso das sanções econômicas contra o Iraque, depois da primeira Guerra do Golfo, que terminaram significando a dupla vitimização da população iraquiana, enquanto Sadam Hussein permanecia inamovível no poder absoluto de seu terror.

Deve ser dada prioridade na elaboração de sanções direcionadas ou "inteligentes"; no sentido de penalizar aqueles que são diretamente responsáveis por atos delitivos, em vez de agravar as duras condições enfrentadas pela população. (FONSECA JR, 1999a, tradução nossa).

O Brasil reconheceu o direcionamento étnico e religioso dos conflitos e somou-se aos esforços de fazer mais efetivas as sanções, os embargos de armas e outras medidas de prevenção dos conflitos armados e proteção da população civil. Esse importante debate deu origem a mudanças de paradigma no encontro entre direitos humanos e segurança coletiva, qual seja, o estabelecimento da punibilidade internacional para graves e massivas violações de direitos humanos durante conflitos armados e fora deles, a concepção das doutrinas do “dever de proteger", ou da "segurança humana" e a volta da antiga discussão grotiana da guerra justa, na figura da "intervenção humanitária”.

O Brasil abraçou a institucionalização da punibilidade para as violações massivas de direitos humanos expressos no Estatuto de Roma; Genocídio, Crimes contra a Humanidade; Crimes de Guerra e Agressão (que ainda não foi tipificado), e aceitou o conceito de segurança humana, ainda que tenha divergido em relação às demais mudanças de paradigma que foram propostas como o “dever de proteger” e a legalização da intervenção humanitária. 


\subsubsection{Serra Leoa e Libéria}

A crise de Serra Leoa se entendeu por muitos anos, porém o golpe militar perpetrado contra o Governo constitucionalmente eleito em 25 de maio de 1997 motivou uma reação enérgica do Conselho de Segurança que declarou que a situação ameaçava a paz e a segurança internacional, decretando sanções como embargo de armas e de fornecimento de petróleo e seus derivados. O Conselho estabeleceu a missão de paz UNOMSIL sob o capítulo VII, ou seja, com a possibilidade de utilizar todos os meios necessários, inclusive a força para restabelecer a paz e a segurança. Na Resolução 1231, o Conselho expressa seu apoio à intervenção da ECOWAS (Economic Community of West African States) através de sua missão de observação ECOMOG, no sentido de restaurar a paz e a segurança no país.

Na crise da África Ocidental, que abarcou principalmente Serra Leoa e Libéria, houve uma estreita colaboração entre o sistema regional de segurança da ECOWAS e o sistema global representado pelo Conselho de Segurança. A missão de paz conviveu com a ECOMOG e cooperou com esta as operações de pacificação, desmobilização e desarmamento da guerrilha RUF. O Conselho de Segurança durante essa crise e, sobretudo, em seus momentos finais, entre os anos de 97 a 99 , com a restauração do governo constitucional incorporou de forma preeminente a preocupação com os direitos humanos, condenando de forma veemente as atrocidades cometidas principalmente pela guerrilha RUF, como o foram: o recrutamento forçado de adolescentes, as mutilações, torturas e a violência sexual entre outros crimes graves.

A ECOWAS igualmente teve participação fundamental na pacificação da Libéria cujo ex-presidente Charles Taylor terminou processado por crimes contra a humanidade no marco do tribunal misto para Serra Leoa, estabelecido depois de finalizado o conflito.

Alguns especialistas consideram a intervenção da ECOWAS em Serra Leoa como o exemplo mais típico de intervenção puramente humanitária. Salta aos olhos o fato de que essa intervenção se deu sob a égide de uma organização regional, que ainda que tenha tido objetivos imediatos puramente humanitários, estaria, certamente, interessada na estabilidade regional e na preservação de sua própria estabilidade. No entanto, ainda que muito tenha que ser estudado sobre a 
experiência de intervenção humanitária em Serra Leoa e Libéria, resta inegável que esta resultou expressivamente positiva e bem sucedida. Ainda que tenha levado vários anos para a estabilização definitiva que se concluiu praticamente em 2004 com o desarmamento, na Libéria um caminho foi aberto para alternativas paralelas ao Conselho de Segurança que não tem se demonstrado capaz de, em escala global, garantir a paz e a segurança internacionais.

No marco de sua participação durante essa, no biênio 1998 e 1999, o Brasil apoiou ativamente os esforços do Conselho e corroborou o apoio ao papel de protagonismo da ECOWAS na pacificação regional.

Durante o convulsionado biênio 1998-1999, no Conselho de Segurança outro processo aconteceu paralelamente, mas que buscava as respostas aos mesmos desafios enfrentados pelo Conselho de Segurança e que, justamente, iriam provocar a ruptura de 1998. Esse processo chamou a atenção da comunidade internacional e polarizou posições, no tema da segurança coletiva e da pacificação dos conflitos e dos desafios surgidos no pós-Guerra Fria. A Conferência de Roma para o estabelecimento do Tribunal Penal Internacional será tratada em capítulo separado por sua relevância fundamental. Muitos países e dois membros do Conselho abraçaram a resposta multilateral e institucional como uma primeira resposta ao genocídio e aos crimes contra a humanidade, a responsabilização penal internacional dos agentes desses crimes, inclusive chefes de Estado. Essa revolução paradigmática nos mecanismos de punibilidade internacional começou com o caso Pinochet, iniciado com sua prisão em Londres, a pedido da justiça espanhola, em 1998 (CARNEIRO, 1998).

Os Estados Unidos, a Rússia e a China não ratificaram o Estatuto de Roma e protagonizaram a ruptura sobre Kossovo no ano seguinte. A comunidade internacional se dividia, o sistema de segurança coletivo sofria uma grande fratura, preso aos paradigmas da Guerra Fria e surgiam respostas a margem do Conselho de Segurança. Esta mesma combinação, a alternativa de justiça internacional e a resposta ao genocídio, geraria a decisão mais controversa do Brasil, talvez na história de suas participações no Conselho de Segurança, a abstenção no caso Darfur. 


\subsection{A Conferência de Roma 1998}

A Convenção contra o genocídio de 1948, refletindo o entusiasmo com a possibilidade de uma justiça internacional mais consistente no imediato pós-guerra com a marcante experiência do Tribunal de Nuremberg, previu em seu artigo IV o estabelecimento de um Tribunal Penal Internacional, o qual teria jurisdição sobre o crime de genocídio, declarado por ela como um crime internacional. A elaboração dos princípios de Nuremberg em 1950 forma parte desse esforço de consolidação que culminou no primeiro, "esboço de Código sobre os Crimes contra a Paz e a Segurança da Humanidade", finalmente submetidos pela Comissão de Direito Internacional à Assembléia Geral das Nações Unidas em 1954. Pouco tempo depois, tensões derivadas da Guerra Fria e discrepâncias insuperáveis sobre a definição do crime de agressão levaram a Assembléia Geral a suspender os trabalhos que não foram retomados até 1989 (SCHABAS, 2004, p. 9).

Um pedido de Trinidad e Tobago preocupados com o tráfico de drogas transnacional ofereceu a oportunidade de reiniciar o trabalho interrompido pela Comissão de Direito Internacional sobre um Tribunal Penal Internacional, no contexto do trabalho prévio sobre um código de crimes contra a humanidade (CASSESE, 2005, p. 17). O Projeto de Código de 1954 era direcionado a tipificar os crimes internacionais que efetivamente ameaçassem a paz e a segurança da humanidade, como agressão, genocídio, crimes contra a humanidade e crimes de guerra. Uma versão revisada do Código foi submetida em 1994.

O vácuo que prevaleceu no Direito Internacional, no período da Guerra Fria sobre estes crimes gravíssimos, levou a uma série de atrocidades que restaram impunes ou foram parcamente investigadas e punidas de forma extemporânea. Não houve qualquer enfoque na prevenção de violações massivas de direitos humanos nesse período e, é consenso entre os especialistas na matéria que a impunidade que prevaleceu durante toda a Guerra Fria, o que, consequentemente, encorajou a recorrência de abusos, uma vez que priva os direitos humanos e o direito internacional humanitário de seu papel preventivo (LAWYERS, 1998). O impulso final para o consenso em direção ao estabelecimento do Tribunal Penal Internacional foi, inegavelmente, fornecido pelo estabelecimento dos tribunais ad hoc para Ruanda e Iugoslávia. 
No Brasil, desde 1998, o ambiente foi se enveredando em direção a um debate político-jurídico favorável à ratificação do Estatuto de Roma do Tribunal Penal Internacional, ainda que alguns institutos previstos pelo Estatuto de Roma poderiam vir encontrar certa incompatibilidade legal com a Constituição Federal de 1988.

As principais controvérsias entre o Estatuto de Roma e a Constituição Brasileira se dão em torno de algumas previsões polêmicas do Estatuto: a pena de prisão perpétua, a entrega de nacionais ao Tribunal e a possibilidade, ainda que remota, de duplo julgamento pelo cometimento do mesmo crime e as imunidades em geral, e relativas ao foro por prerrogativa de função. Mesmo durante a conferência, a diplomacia brasileira, apesar de ter inicialmente proposto o termo extradição para a entrega de pessoas acusadas pelo Tribunal, rapidamente reviu sua posição no sentido de evitar a incompatibilidade com a Constituição que proíbe a extradição de nacionais.

Com efeito, o debate técnico, mesmo dentre as delegações, uma vez que outros países possuem limitações semelhantes em seus ordenamentos jurídicos internos, centrou-se na diferenciação básica entre o tradicional instituto da extradição e a entrega a uma jurisdição multilateral, criada pelos próprios Estados membros.

A extradição constitui instituto de cooperação entre estados de natureza bilateral na qual o acusado é entregue a outra jurisdição soberana, da qual o Estado que extradita não participa. Portanto, a polêmica foi resolvida a partir de uma proposta do Reino Unido que diferenciou os institutos e criou a figura da "entrega" (surrender) à jurisdição internacional, de natureza multilateral e participativa, expresso no artigo 102 do Estatuto.

Outro ponto de divergência foi a adoção da pena de prisão perpétua que o Brasil não admite em seu direito interno. Essa dificuldade foi parcialmente mitigada pelo dispositivo do artigo 110, o qual prevê a possibilidade de revisão da pena, uma vez cumpridos 25 anos (JARDIM, 2006, t. 1).

No mesmo sentido, observadores da sociedade civil, organizada na Conferência dos Plenipotenciários, reconheceram que o Ministério das Relações Exteriores (MRE) estabeleceu constante diálogo com a sociedade civil desde momentos preparatórios à Conferência, em especial, durante a III ${ }^{\text {a }}$ Conferência Nacional de Direitos humanos. 
Essa participação da sociedade civil num tema tão estratégico de política externa foi um fato inédito no Brasil. Alguns autores que participaram da Conferência, como Dal Maso Jardim, consideraram que, em grande parte, as reivindicações da sociedade civil foram atendidas pelo MRE, ainda que alguns temas polêmicos do TPI não estivessem definidos. Entre eles, podemos citar a natureza da competência da Corte e o caráter de sua jurisdição, e o papel do Conselho de Segurança das Nações Unidas. Destaca que, no Seminário Oficial do Ministério das Relações Exteriores sobre o assunto, organizado em conjunto com o Conselho da Justiça Federal, "a atuação da diplomacia brasileira e boa parte da intelectualidade deste país demonstrou claro ânimo, consentimento e desejo, em relação à ratificação do TPI pelo Brasil”. A boa relação persistiu durante a Conferência, propiciando que a delegação brasileira comparecesse, à "Sudan Room" a fim de dialogar com as Organizações não-governamentais atuantes naquele momento.

Por outro lado, no âmbito do poder legislativo, o Presidente da Comissão de Direitos Humanos da Câmara dos Deputados, deputado Nilmário Miranda, apresentou no ano 2000 a publicação "O que é o Tribunal Penal Internacional?", na qual afirmou que a campanha pela criação do Tribunal Penal Internacional tinha sido uma das lutas mais importantes dessa Comissão no plano internacional desde 1999 por meio da realização de diferentes eventos, de articulações e da defesa do Tribunal em importantes foros internacionais e nacionais (FREITAS, 2005). Portanto, o processo de discussão sobre TPI, incluindo seminários e audiências públicas na Câmara dos Deputados, esclareceu os legisladores e se constituiu em fator preponderante para a assinatura do Estatuto por parte Brasil e, naquela ocasião, clamou para "que as convicções do Executivo, após acalorado e profundo debate, inspirem a pronta aprovação deste Estatuto pelo Congresso Nacional" (MIRANDA, 1997, p. 8).

Ou seja, o processo de elaboração e ratificação do Estatuto de Roma foi marcado pelo entusiasmo com essa nova dimensão do Direito Internacional como uma resposta aos grandes problemas de segurança e direitos humanos que podem ameaçar a estabilidade mundial. A experiência do Brasil como participante não permanente do Conselho nos momentos críticos de Ruanda e Iugoslávia certamente contribuiu para a formação desse consenso. 
Portanto, como um desfecho previsível do movimento geral favorável à ratificação, após a adoção do Estatuto de Roma, em julho de 1998, o Brasil assinou o Tratado em 2000, ratificando-o em junho de 2002.

\subsection{Biênio 2004 - 2005}

No oeste do Sudão, na província de Darfur, desde os anos noventa, uma combinação explosiva de prolongadas secas, conflitos étnicos entre as comunidades de pastores nômades e agricultores sedentários e o favorecimento sistemático da minoria árabe no poder provocaram tensões com outros grupos, principalmente com as etnias majoritárias na região, Zaghawa, Massalit e Fur ${ }^{2}$ e jogou um papel fundamental no desencadeamento da rebelião armada (PRUNIER, 2005).

Em fevereiro de 2003, após violenta reação das forças governamentais a um ataque rebelde a instalações governamentais, 200 mil pessoas cruzaram a fronteira do Chade com o Sudão. A surpresa da comunidade internacional com um conflito inesperado provocou a demora na ajuda aos refugiados, os sistemas de alerta não haviam acusado a iminência de crise na região. Contraditoriamente, o Sudão era motivo de otimismo, pois a assinatura de acordos de paz colocara um termo a mais de 20 anos de guerra na região sul do país (FLINT; DE WAAL, 2002). A crise de Darfur começou de forma surpreendente também para o Brasil que participava do otimismo, tendo enviado militares para integrar a missão de observação dos acordos de paz do sul do Sudão.

O caldeirão étnico que envolve os vizinhos Chade, Sudão e República Centro Africana, na região do Sahel, onde existe a presença dos mesmos grupos, depois se revelaria um fator de expansão do conflito, provisão e apoio de uma e outra parte, treinamento e apoio material, numa situação de insegurança regional, transformando os três países em bases operacionais para os respectivos grupos armados, assim como a presença de enfrentamentos e incursões de fronteira e ataques a vilarejos fronteiriços.

\footnotetext{
${ }^{2}$ A palavra Darfur faz referência a este grupo; Dar significa: Terra. Portanto, Darfur e a terra dos Fur igualmente existem: o Dar Massalit e o Dar Zaghawa, mas o nome oficial da província foi baseado nos fur que habitam no centro-oeste de Darfur.
} 
Em pouco tempo, a crise de Darfur se transformava na maior crise humanitária do mundo e no primeiro genocídio do século XXI e, mais uma vez, o Conselho de Segurança foi confrontado com as debilidades estruturais e paradigmáticas que o assediam desde o final da Guerra Fria.

Os Estados Unidos já haviam entrado na era Bush e, depois dos atentados do dia 11 de setembro, sua postura também mudou significativamente. $\mathrm{O}$ unilateralismo militar tinha provocado uma nova ruptura no sistema de segurança coletiva, agora muito mais contundente, sem a justificativa moral dos crimes contra a humanidade ocorridos na Bósnia ou Kosovo. A invasão do Iraque encheu de incertezas o mundo, deslegitimou tanto o Conselho de Segurança, como a emergente doutrina do "dever de proteger", colocando à mostra todos os seus perigos decorrentes da possibilidade do mau uso da intervenção humanitária com base em argumentos duvidosos não comprovados, ou diretamente falsos, como ocorreu no Iraque. Todavia, as tentativas de caracterizar essa intervenção como humanitária foram bastante tímidas e prontamente rechaçadas pela comunidade internacional, e de forma contundente pela sociedade civil, notadamente as organizações mais respeitadas no campo da defesa dos direitos humanos. ${ }^{3}$

Os Estados Unidos, apesar de todas as suas divergências, tinham assinado o Tratado de Roma no último dia da administração Clinton: mudou de posição e passou a uma oposição ferrenha ao Tratado e à busca de acordos bilaterais de imunidade para cidadãos e militares americanos, pressionando os países menores que tinham ratificado o tratado do TPI.

No entanto, a comunidade internacional foi confrontada com um novo genocídio para o qual ela não tem uma política de segurança clara, nem doutrina, nem propostas de como pacificar esse tipo de conflito. Contrastando com a oposição dos americanos ao TPI, numa iniciativa inédita, o próprio Conselho em sua fase unipolar; liderado pelos Estados Unidos, resolve lançar mão de um artigo do Estatuto de Roma que permite ao Conselho de Segurança referir casos ao Tribunal, independente da ratificação dos Estados envolvidos. Importante ressaltar que, entre os membros permanentes do Conselho de Segurança, Estados Unidos, Rússia,

\footnotetext{
${ }^{3}$ A organização de direitos humanos Human Rights Watch publicou um texto exclusivamente para rechaçar qualquer possibilidade de apresentar a invasão do Iraque como uma intervenção humanitária.
} 
China, França e Reino Unido, apenas os dois últimos fazem parte no tratado que estabeleceu o TPI.

Essa iniciativa exigia bastante coragem uma vez que o Sudão, não é parte do TPI o que por si só traz contradições e questionamentos de princípio do Direito Internacional. Igualmente, no espírito de proteger o mundo todo do genocídio e dos crimes contra a humanidade, o Estatuto de Roma contém uma inovação ousada ao estabelecer a autorização para que o Conselho refira casos diretamente ao TPI, sem o consentimento dos Estados.

O precedente era extremamente controverso, principalmente para os Estados Unidos que, apesar de estar protegido pelo veto, referir um caso contra um Estado não membro do tratado representaria um precedente de universalidade da jurisdição do TPI.

Por outro lado, qualquer proposta de uso da força contra o Sudão seria bloqueada pela China que possui interesses no Sudão, sobretudo nos setores de gás e petróleo e tem sido uma potência emergente e sem muito zelo pelos padrões de respeito aos direitos humanos nos países nos quais seus interesses se expandem. No entanto, bloquear a iniciativa de punibilidade já seria muito evidente e tanto a China como a Rússia não se opuseram.

Os Estados Unidos se somaram ao consenso diante da impotência do Conselho em ter propostas para deter o genocídio de Darfur. No entanto, os Estados Unidos aproveitaram para exigir que a resolução incluísse a propalada imunidade para seus cidadãos e forças militares. O debate provocou uma discórdia sem precedentes no Conselho e conseguiu dividir inclusive os países participantes que apóiam de forma resoluta a afirmação da justiça internacional representada pelo TPI.

Ao final, o Brasil decidiu abster-se na votação mais crucial tomada pelo Conselho de Segurança no novo século. O Brasil, não sendo membro permanente, pode abster-se sem bloquear a resolução, pois não dispõe de veto. No entanto, a marcação de posição sobre a igualdade de todos os Estados perante o Direito Internacional, diante dos Estados Unidos, no sentido de que nenhuma imunidade unilateral seria tolerável, teve um alto custo. Não faltaram especulações a respeito de uma possível agenda oculta na controversa posição que o Brasil resolveu adotar 
diante desse dilema. Como um apoiador entusiasta do TPI e das medidas legais no âmbito da justiça internacional e como um país que vinha manifestando reservas às propostas de uso da força em crises humanitárias, essa posição não fazia o menor sentido.

O Brasil se apressou em pronunciamentos oficiais e, mesmo no corpo da resolução a esclarecer seu voto, declarou que era totalmente a favor da apresentação do caso ao TPI, no entanto, a concessão de imunidade exigida pelos Estados Unidos não era aceitável. Nesse sentido, foram as declarações do representante do Brasil:

A manutenção da paz e a segurança internacional e a luta contra a impunidade não podem ser vistas como objetivos conflitantes. O Brasil reitera que o TPI proporciona todos os salvaguardas e equilíbrios para prevenir possíveis abusos e qualquer uso político de sua jurisdição. Portanto os esforços para assegurar imunidades mais amplas da jurisdição da Corte são duvidosas e contraproducentes, na nossa visão. (SARDENBERG, 2005, tradução nossa).

Não faltaram insinuações de que o Brasil estaria entrando numa dinâmica de "vale tudo" para integrar de forma permanente o Conselho de Segurança, e o voto do Sudão estaria por trás da insólita, porém, coerente posição brasileira. Chegou-se a mencionar negociações da Petrobrás para exploração de petróleo no Sudão, o que já constitui um evidente exagero conspirativo, uma vez que a Petrobrás não opera no Sudão e as negociações ocorrem com vários países, como prática das grandes empresas em busca de oportunidades de investimento, sem que isso necessariamente signifique algo, do ponto de vista de política externa. No entanto, uma recente visita de representantes do Brasil ao Sudão, em que o apoio para integrar o Conselho estaria na pauta, forneceu argumentos para a teoria da agenda oculta, que provavelmente jamais será comprovada, ou rejeitada totalmente.

Por outro lado, a posição do Brasil envolveu um cálculo maduro no sentido de preservar a integridade do recente e, ainda em fase de afirmação, Tribunal Penal Internacional. A efetividade da apresentação da situação ao TPI como forma de distensão do conflito não estava comprovada; a abstenção do Brasil não impediria a apresentação do caso, e o Brasil optou por marcar uma posição de princípio em favor da integridade da jurisdição do TPI e impedir precedentes que teriam uma dinâmica, talvez, incontrolável. A luta contra a impunidade e a manutenção da paz 
não são conflitantes, mas também não são a mesma coisa. No entanto, muitos anos depois, a reação do Sudão, tentando negociar um cessar fogo, após o processamento do presidente Omar Al-Bashir por genocídio e crimes contra a humanidade, deixa entrever que as duas coisas podem estar mais relacionadas que se podia vislumbrar num mundo onde prevalecia a impunidade para chefes de Estado e outras figuras, atuando em capacidade oficial.

O posterior enfraquecimento dessas gestões do governo americano também deve ser um elemento de análise na difícil avaliação de uma decisão que somente a história poderá julgar, e deslindar se o Brasil esteve correto em preferir a preservação do TPI. A preocupação do Brasil com esses crimes hediondos que têm ocorrido no pós-guerra fria, no entanto, não pode ser questionada de forma razoável.

\section{Missões de paz}

A incorporação da dimensão humana da segurança coletiva avança no sentido de mudar a configuração das missões de paz. Mandatos específicos para proteger populações civis, refugiados e deslocados internos, assim como pessoal humanitário, passaram a ser fundamentais nas novas missões de paz. Um exemplo digno de nota é a MINUSTAH no Haiti, liderada pelo Brasil na qual o mandato inclui estabilização, promoção da democracia e dos direitos humanos. Nesse sentido, a constituição da MINUSTAH/Direitos Humanos foi um passo importantíssimo na incorporação dos direitos humanos como parte dos objetivos da missão de paz. No entanto, esse componente tem enfrentado desafios desalentadores em sua parca implementação (TEIXEIRA, 2007). A constituição da EUFOR, a missão de paz para o Chade e República Centro Africana, com mandato incluindo dois países para proteger refugiados e deslocados internos, marca também o novo enfoque das missões de paz.

Do sucesso dessas missões dependerá em grande parte a consolidação dos emergentes como interlocutores fiáveis e efetivos no cenário da segurança coletiva e a eventual institucionalização de um novo multilateralismo em matéria de segurança coletiva internacional. Todos os emergentes do sul investem na legitimidade como um componente não somente intrínseco do sistema de segurança coletiva, mas também de sua proposta como aspirantes a esteios da segurança coletiva. 
A emergência da doutrina do "Dever de Proteger", que propõe a legalização da intervenção humanitária, igualmente constitui um desenvolvimento interessante, porém controverso. Essa doutrina elaborada por um painel de especialistas auspiciada pelo Canadá subordina a soberania à proteção de suas populações (JUBILUT, 2007b) e muda o enfoque da segurança do Estado para as pessoas, no inovador conceito de "segurança humana", pretendendo ser um poderoso instrumento de dissuasão contra o genocídio e os crimes contra a humanidade (OLIVEIRA, 2006). A Assembléia Geral terminou por incluir o dever de proteger em sua Resolução sobre a Reforma da ONU em 2005.

Este tem sido o ponto de inflexão do Brasil em sua busca da legitimidade na proteção dos direitos humanos na segurança coletiva. Seu caráter elitista no sentido de que, na prática, pode significar apenas intervenções de países ricos sobre países pobres, e as possibilidades de abuso devido à total ausência de critérios práticos aplicados, ou seja, quando é justificada uma intervenção, como saber se haverá um genocídio ou um crime contra a humanidade que pode motivar as reticências do Brasil e de outros países.

Por outro lado, o Canadá tem tido um protagonismo doutrinário único no sistema de segurança coletiva devido ao seu papel destacado e amplamente superior a todos os outros emergentes no campo doutrinal das reformas no sistema de segurança coletivo. No entanto, o Canadá não propõe reformas estruturais no Conselho como sua ampliação, não tem papel regional de segurança e não pretende um protagonismo no sistema (SAUERBRONN, 2006).

O Canadá constitui um caso atípico de proposta de reforma sem reforma da estrutura, e ele mesmo renuncia ao protagonismo em matéria de segurança coletiva, ainda que seu papel seja extremamente original e influente.

\section{Ampliação do Conselho de Segurança?}

Desde 1944, debate-se sobre a integração do Brasil ao Conselho de Segurança, quando o Secretário de Estado Americano Cornell Hurell aventou essa possibilidade nas conferências prévias ao final da II Guerra. Posteriormente, essa idéia não foi discutida seriamente até o final do século XXI, quando o Brasil começou a, 
efetivamente, mudar o seu papel no cenário internacional. Possivelmente, alguns países não estejam interessados nas mudanças na composição do Conselho e os esforços para bloquear o debate aberto têm sido duramente criticados pelo Brasil que manifesta, de forma pouco usual nesse tema, uma atitude desafiante e mesmo combativa. Prestes a começar seu novo período no Conselho em 2003, o Brasil já demonstrava sua impaciência diante dos parcos resultados do grupo de trabalho formado para estudar a reforma do Conselho.

Os temas tratados são realmente complexos e envolvem muitas dificuldades, mas isto não nos deve desanimar em continuar a buscar desenvolvimentos institucionais que reflitam de forma adequada as realidades políticas e de segurança do século XXI e, que possam representar melhor nossas concepções e interesses. (SARDENBERG, 2003, tradução nossa).

Por meio de um esforço coordenado, o Presidente Lula já tinha defendido a reforma do Conselho em seu pronunciamento diante da Assembleia Geral, colocando-a como uma tarefa urgente diante dos riscos para a ordem política internacional. Nesse sentido, o presidente advogou pelo reconhecimento dos emergentes na cena internacional que têm se tornado atores relevantes ou que, frequentemente, desempenham um papel fundamental na resolução pacifica de conflitos. ${ }^{4}$

O próprio Secretário Geral da ONU, Kofi Annan (2003, tradução nossa), participou do debate de forma enérgica, no final de seu período.

Eu respeitosamente lhes sugiro Excelências, que aos olhos de nossos povos a dificuldade de chegar a um acordo não nos desculpa do fracasso de fazê-lo. Se vocês querem que as decisões do Conselho sejam mais respeitadas, particularmente no mundo em desenvolvimento, vocês precisam considerar o tema de sua composição com maior urgência. ${ }^{5}$

A representação equitativa, como ponto de partida, transformou-se num grande debate no seio do sistema de segurança coletivo, uma vez que o entendimento, principalmente dos emergentes, e sua participação no Conselho pôde dar

\footnotetext{
${ }^{4}$ Pronunciamento do Presidente Luis Inácio Lula da Silva a Assembléia Geral em 23 de Setembro 2003.

${ }^{5}$ Pronunciamento do Secretario Geral da ONU, Kofi Annan ao Conselho de Segurança em 23 de setembro de 2003.
} 
maior legitimidade e valorizar o papel de salvaguardas e promotores regionais de soluções pacíficas de conflitos.

Aos olhos de outros países, o enfoque regional de ampliação e democratização não é suficiente e clama por mudanças paradigmáticas, como o Canadá que prefere a reforma doutrinária à reforma estrutural. Esses dois enfoques ainda não encontraram um ponto de convergência e equilíbrio.

\section{$60 \mathrm{G4}$}

O Grupo do G4, Brasil, Índia, Japão e Alemanha como aspirantes a integrar o Conselho de Segurança, constituem outra novidade no contexto do debate pela reforma no sistema de segurança coletivo.

Apesar de o poderio econômico não ser necessariamente fundível com o poderio militar, e vice-versa, o caso da Alemanha e do Japão coloca elementos de análise complexos. Os dois países possuem considerável arsenal militar e o Japão, particularmente, tem sido um dos países com os maiores gastos militares nos últimos anos. O Japão é o país que mais acumula participações como membro não permanente do Conselho de Segurança. Os tempos são outros, a Guerra Fria acabou, mas sobre eles continua pesando o estigma de potências agressoras na Segunda Guerra Mundial. A negativa de reconhecimento por parte do Japão dos crimes cometidos durante a Segunda Guerra Mundial, sobretudo durante a ocupação da Manchúria e na tomada brutal de Nanquim, compromete sua legitimidade porque coloca em dúvida sua verdadeira renúncia à violência como meio de alcançar poder e influência.

A oposição da China a que o Japão integre o Conselho não será facilmente resolvida, principalmente quando a China, como potência militar e econômica, continua aumentando seu poder, enquanto que o Japão vem perdendo sua pujança econômica desde a crise asiática de 1997, da qual nunca se recuperou totalmente. ${ }^{6}$

A Alemanha, por outro lado, tem demonstrado um comprometimento com a democracia e com a tolerância notáveis, enterrando o racismo e o expansionismo

\footnotetext{
${ }^{6}$ No dia 17 de novembro de 2008, o Japão anunciou oficialmente que sua economia havia entrado em recessão.
} 
que marcaram seu papel desestabilizador na Europa durante 50 anos. O comprometimento da Alemanha com a estabilidade, a paz e a segurança não pode ser questionado, tendo se transformado num esteio de democracia e crescimento no mundo todo no período pós-guerra. No entanto, a presença firme da Europa no Conselho de Segurança mediante a presença do Reino Unido e da Franca, compromete essa aproximação, ainda que o elemento regional não seja o único fator em jogo nessa disputa global.

No entanto, a iniciativa do G4 pode ter mais desvantagens que vantagens e pode significar mais retrocessos que avanços para o Brasil e para a Índia em seu tortuoso caminho em direção ao Conselho. Na atual conjuntura, parece que ninguém entrará no Conselho sem o aval da China, e a aliança com o combalido Japão pode custar mais caro do que se imagina.

\section{Ampliação do Conselho em perspectiva}

O Brasil tem tido uma grande participação em missões de paz das Nações Unidas e tem um dos mais freqüentes históricos de participação como membro não permanente do Conselho de Segurança, com nove participações desde seus primórdios, uma vez que sua primeira participação ocorreu no biênio 1946-1947 e o último, em 2004-2005.

Portanto, durante os 63 anos de existência do Conselho de Segurança, o Brasil esteve presente durante 18 anos, o que inegavelmente significa uma grande familiaridade com os temas tratados pelo Conselho e uma razoável respeitabilidade em suas participações, uma vez que mantém uma linha de continuidade em sucessivas eleições.

O Brasil tem tido uma aproximação fundamentalmente grotiana das relações de segurança internacional com pinceladas de realismo. Investindo pesadamente no multilateralismo e na legalidade internacional, percebe as disparidades de poder como um elemento desestabilizador em si, combatendo a tendência à unipolaridade e ao unilateralismo americano dos últimos anos. Nesse sentido, tem advogado insistentemente pela reforma do Conselho para torná-lo mais democrático e mais representativo. Portanto, ao não contar com ameaças 
reais, o Brasil vê a atual estrutura do sistema como um problema de segurança devido às disparidades de poder no contexto global da segurança internacional. Apesar de o Conselho jamais ter sido pensado para ser democrático e sim para garantir a segurança, ainda assim, a insistência do Brasil é positiva para ir vencendo as resistências de reforma num sistema fundamentalmente obsoleto.

A vantagem do Brasil em seu contexto regional específico reside na baixa conflitividade da região (América do Sul) nos últimos 30 anos. Guerras inter-estatais praticamente não ocorreram nos últimos 50 anos, sendo que o último confronto ocorreu em 1995 entre Equador e Peru que permanece com uma exceção no pós-guerra. O longo conflito na Colômbia, que guarda fios de continuidade desde um século com a Guerra dos Mil Dias entre liberais e conservadores, terminou em 1903 e, praticamente em conflito contínuo desde 1948, aberto depois do Bogotazo, ${ }^{7}$ permanece como o grande desafio. O mal estar causado pelo ataque de "Angostura" onde a Colômbia violou a integridade territorial do Equador e provocou o rompimento das relações diplomáticas, fortemente apoiadas pela Venezuela, aparece como exceção, mas que pode mudar esta tendência de baixa conflitividade. O Brasil timidamente tem se aproximado da Colômbia, mas ainda não se constituiu em mediador consistente.

Da mesma forma, o papel do Brasil como líder da MINUSTAH, no Haiti, tem sido muito importante no sentido da confiança depositada pela comunidade internacional na possibilidade de estabilização de um país cronicamente instável desde a caída do regime ditatorial dos Duvalier (Baby Doc) em 1986. Sintomaticamente, a primeira missão comandada pelo Brasil ocorre dentro de um contexto regional (CERVO, 2008). O novo enfoque da MINUSTAH como uma missão de novo tipo, com componentes de direitos humanos e desenvolvimento, aumenta suas possibilidades de sucesso, ainda que reste o desafio de implementar as propostas deste novo tipo de missão de estabilização, o que não tem dado mostras de ser tarefa fácil.

O Brasil tem se firmado como potência econômica regional, porém isso não tem se traduzido no contexto da segurança regional uma vez que o Brasil ainda

\footnotetext{
${ }^{7}$ Revolta popular que destruiu a cidade de Santa Fé de Bogotá, capital da Colômbia, depois do assassinato do candidato do partido liberal, Elieser Gaitán, que representava as classes médias e a emergente elite comercial urbana.
} 
não se afirmou como uma garante da estabilidade regional. Por outro lado, um reequipamento das Forças Armadas Brasileiras poderia dar maior consistência em sua posição como garante da paz regional ainda que baseado em sua vontade mediadora e não no uso da força.

O pertencimento ao Conselho de Segurança tem se transformado na grande panaceia do Brasil em matéria de segurança internacional. A reforma do Conselho tem sido vista pelos países do Sul, Brasil, Índia e África do Sul, como a institucionalização de seu status no concerto das nações. Esse ponto de vista reducionista pode ser sua grande armadilha.

A postura do Canadá, silenciosa e influente, demonstra que a reforma do Conselho pode não constituir um fim em si mesmo. O Canadá, sem reivindicar sua integração no Conselho, tem sido muito mais influente em seus rumos, uma vez que vem dando um passo fundamental. Começou a enfrentar o desafio de pensar numa nova doutrina de segurança coletiva que corresponda às necessidades do mundo atual, unipolar incompleto, multipolar desigual, mas fundamentalmente sem uma definição segura sobre si mesmo que lhe permita pensar em sua própria segurança.

Historicamente notamos com particular acuidade que o processo de expansão da ONU não correspondeu a uma maior participação nos temas de segurança coletiva. A democracia da Assembléia Geral, na qual o voto de um pequeno país desarmado como o Butão vale o mesmo que o dos Estados Unidos, não guarda qualquer relação com o elitismo do Conselho de Segurança, muito mais realista e muito menos representativo. No entanto, essas discrepâncias guardam estreita relação com a realidade e o normativismo, que nem sempre funcionam nos mesmos termos, quando se trata de relações de força que constituem a fronteira do Direito Internacional. Os desníveis de desenvolvimento e poder no mundo determinam parte dessa institucionalidade particular.

Em 1945, a ONU contava com a participação de 51 países. Em 1960, já eram 99 países; em 1975, foram 144 países; em 1990, foram 159 países com as adesões de Liechtenstein e Namíbia.

Em 2006, com a adesão de Montenegro, a ONU chegou aos 192 países membros, ou seja, 141 países, 76,5\% de todos os países do mundo atual, não eram 
membros, ou não existiam, quando o Conselho foi estabelecido, mas todos se tornaram membros da Assembléia Geral. Portanto, a discrepância entre o órgão político, democrático e representativo da ONU e seu órgão de segurança mais pragmático e baseado em critérios de poder se estendeu de forma notável.

Portanto, no mundo, 74 países, ou seja, 38,5\%, quase metade de todos os países da comunidade de Estados, nunca foram eleitos membros não permanentes do Conselho de Segurança. Por outro lado, os emergentes refletem uma real, aceita e gradualmente participativa atuação em temas de segurança internacional. O Japão acumula 10 participações como membro não permanente. O Brasil acumula nove participações; a Argentina, oito; a Índia, Canadá, Colômbia, Itália e o Paquistão, seis participações; a Alemanha, Austrália e Dinamarca, quatro participações. Ou seja, todos os emergentes, sejam participantes do IBSA ou do G4, aparecem como ativos participantes, como membros não permanentes do Conselho de Segurança. A única exceção é a África do Sul, o que pode ser explicado pela sua recente democratização em 1994 e, portanto, recente aceitação nos círculos internacionais de segurança coletiva.

Com efeito, os emergentes buscam a oficialização de um processo de emergência que ocorre não apenas na realidade das relações internacionais, mas tem sido parcialmente institucionalizado pela prática reiterada dos Estados. As contínuas eleições desses países demonstram que o mundo tem confiado neles para resguardar sua segurança, e suas contínuas eleições têm demonstrado consistência e permanência. De certa forma, acumularam maior legitimidade que os membros permanentes que não precisam obter o consenso da comunidade internacional. No entanto, a lógica da segurança nem sempre pode ser vista de forma normativa e representativa.

As aspirações do Brasil e de outros emergentes, postulando mais representatividade e transparência no Conselho, fazem sentido, porém num contexto de segurança importantes relativismos devem ser levados em conta. Segurança e pacificação exigem o exercício de poder formal, capacidade de impor pela força as decisões tomadas em nome da segurança coletiva. $\mathrm{O}$ enfoque democrático e universalista pode ser ingênuo para um mundo pleno de ameaças concretas.

Por outro lado, o exemplo discreto do Canadá deve ser levado em consideração. A reforma do Conselho tem mais chances de ser efetuada à medida que se 
coloquem os fins além da representatividade, sim com o intuito de re-fundar um sistema eficiente de segurança coletiva. Parecendo apenas uma reivindicação para expressar os desejos de maior poder dos emergentes, não proporciona, por si só, maior eficiência ao sistema como um todo. A reforma estrutural deve ser acompanhada de uma renovação doutrinária da segurança coletiva internacional, que incorpore sua dimensão humana da prevenção do genocídio e dos crimes contra a humanidade a estabilidade e ameaças assimétricas. O Conselho de Segurança não é um órgão representativo. O sistema de segurança coletivo não foi pensado para ser democrático, nem representativo, nem plural; ele foi pensado para manter o equilíbrio de poder e garantir a paz e a segurança coletiva, evitando guerras e prevenindo conflitos, por meio da resolução pacífica de conflitos.

A globalização e o aumento da interdependência econômica torna mister o estabelecimento de um sistema de segurança coletivo condizente com esse fato inexorável. Os genocídios e conflitos anárquicos, falências de Estados inteiros, clamam por mudanças paradigmáticas e estruturais que sejam capazes de implementar um novo sistema de segurança. Sem que as propostas de ampliação contemplem uma maior eficiência do sistema, dificilmente será uma base para um novo consenso coletivo. O Brasil, assim como os outros países aspirantes ao Conselho, deve buscar esse equilíbrio em uma proposta estrutural que se combine com um novo consenso em torno dos desafios da segurança coletiva no século XXI, buscando um maior conteúdo de segurança humana e coletiva que precise de uma nova estrutura ampliada para sua implementação e funcionamento.

\section{Face to face with the Crime: brazilian foreign policy in face of the crimes against humanity in the post-cold war period: from humanitarian intervention to the reform of the Security Council}

\section{Summary}

The present article describes and analyses the positions of Brazilian diplomacy in face of the great humanitarian tragedies which affected the world in the post-cold war period. Arguably it concentrates in the contents of Brazilian participation in the United Nations Security Council during the historic period which saw great challenges to the security system like the crises in the former Yugoslavia, East 
Timor, and Kosovo and recently the daring decision about Darfur in 2005. Without the ambition to a deep analysis, once it touches issues being currently debated in international fora, the article establishes some directions for analytical follow up. We conclude that Brazil is improving its policy towards the security system but lacks a response to the serious ethno political conflicts which proliferated in the post-cold war period, as the international community as a whole does not have.

Keywords. Humanitarian Intervention. Security Council.

\section{Referências}

ANJOS, Claudia Giovannetti Pereira. Atuação do Conselho de Segurança da Organização das Nações Unidas nas crises humanitárias na década de 1990. Dissertação (Mestrado)- Faculdade de Direito da Universidade de São Paulo, 2007.

BOZIC-ROBERTSON, Agnez. Words before the war: Milosevic's use of mass media band rhetoric to provoke ethno political conflict in former Yugoslavia. East European Quarterly, [S.1.], v. 38, n. 4, dez. 2004.

BRIGADÃO, Clovis; MELLO, Valerie de Campos. Diplomacia cidadã, panorama brasileiro de prevenção de conflitos internacionais. Rio de Janeiro: Gramma; Fundação Konrad Adenauer, 2006.

CANÇADO TRINDADE, Antonio A. A proteção internacional dos direitos humanos e o Brasil. Brasília: Universiade de Brasília, 1998.

CARNEIRO, Wellington Pereira. O caso Pinochet ameaça a impunidade internacional. Jornal Vale Paraibano, São José dos Campos, ago. 1998

CASSESE, Antonio. De Nuremberg a Roma: dos Tribunais Militares Internacionais ao Tribunal Penal Internacional. In: AMBOS, Kai; CARVALHO, Salos (Org.). O direito penal no estatuto de Roma. Rio de Janeiro: Lumen Juris, 2005.

CERVO, Amado Luiz; BUENO, Clodoaldo. História da política exterior do Brasil. 3. ed. Brasília: Universidade de Brasília, 2008.

COSTA VAZ, Alcides (Ed.). Intermediate states, regional leadership and security: India, Brazil and South Africa. Brasília: Universiade de Brasília, 2006.

DALAIRE, Rome. Shake hands with the devil. Londres: Arrow Books, 2003. 
FLINT, Julie; DE WAAL, Alex. Darfur: a new history of a long war. Londres; Nova York: Zed Books, 2002.

FONSECA JR., Gelson. Protection of civilians in armed conflicts, statement by His Excellency Ambassador. New York: [s.n], set. 1999a.

FONSECA JR., Gelson. The situation in Kosovo, Federal Republic of Yugoslavia Statement by His Excellency Ambassador. New York: [s.n], jun. 1999b.

FREITAS, Chistiana Galvão Ferreira de. O Tribunal Penal Internacional permanente e a proteção dos direitos humanos: o debate sobre a ratificação do Tratado no Brasil em Perspectiva Comparada. Campinas, 2005. Dissertação (Mestrado)Departamento de Ciência Política do Instituto de Filosofia e Ciências Humanas da Universidade Estadual de Campinas, UNICAMP. Campinas, 2005.

GURR, Ted Robert. Peoples versus states, minorities at risk in the new century. Washington DC: United States Institute of Peace, 2000.

HARFF, Bárbara; GURR, Ted Robert. Ethnic conflict. In: WORLD politics. Boulder; Oxford: Westview, 2004.

JARDIM, Tarciso dal Maso. O Brasil e o direito internacional dos conflitos armados. Porto Alegre: S. A. Fabris, 2006. t. 1.

JARDIM, Tarciso Dal Maso. O Tribunal Penal Internacional e a sua importância para os direitos humanos. In: BRASIL. Câmara dos Deputados. Comissão de Direitos Humanos. O que é o Tribunal Penal Internacional? Brasília: Coordenação de Publicações, 2000.

JUBILUT, Liliana Lyra. A legitimidade do principio de não-intervenção em face das Resoluções do Conselho de Segurança das Nações Unidas. São Paulo, 2007. Tese (Doutorado)- Faculdade de Direito da Universidade de São Paulo, São Paulo, 2007a.

JUBILUT, Liliana Lyra. O direito internacional dos refugiados e sua aplicação no ordenamento jurídico brasileiro. São Paulo: Método, 2007b.

LAFER, Celso. A identidade internacional do Brasil e a politica externa brasileira: passado, presente e futuro. São Paulo: Perspectiva, 2007.

LAWYERS COMMITTEE FOR HUMAN RIGHTS. Establishing and International Criminal Court, major unresolved issues in the Draft Statute, International Criminal Court. Briefing Series, [S.1.], v. 1, n. 1, maio 1998. 
OLIVEIRA, Odete Maria de (Org.). A configuração dos humanismos e relações internacionais. Ijui: Unijui, 2006.

PRUNIER, Gerard. Darfur: the ambiguous genocide. Ithaca: Cornell University, 2005.

RATNER, R.; STEFEN; ABRAMS, Jason S. Accountability for human rights atrocities. Internacional Law, Oxford, 2001.

SARDENBERG, Ronaldo Mota. Question of equitable representation on and increase in the membership of the Security Council and related matters. New York: United States, out. 2003. Permanent Representative of Brazil to the UN, Security Council.

SARDENBERG, Ronaldo Mota. Statement of Brazil on the referral of the International Commission of Inquiry on Darfur to the International Criminal Court. New York: United States, mar. 2005. Permanent Representative of Brazil to the UN, Security Council.

SAUERBRONN, Christiana. A responsabilidade de proteger. In. BRIGADÃO, Clovis; MELLO, Valerie de Campos (Org.). Diplomacia cidadã, panorama brasileiro de prevencão de conflitos internacionais. Rio de Janeiro: Gramma; Fundacao Komrad Adenauer, 2006.

SCHABAS, Willian. An introduction to the international criminal court. 2. ed. Cambridge: Cambridge University, 2004.

TEIXEIRA, Marcella Cunha. Os desafios da Minustah no Haiti. Brasília, 2007. Trabalho de Conclusão de Curso (Graduação)- Centro Universitário de Brasília, Brasília, 2007.

UNITED NATIONS. Economic and Social Council. Commission on human rights, fiftieth session, extrajudicial, summary or arbitrary execution. Rwanda, 11 August 1993. (E/CN.4/1994/7/Add.1).

VALLE, Henrique. Statement by his excellency ambassador Henrique Valle, deputy permanent representative of Brazil to the United Nations. New York: [s.n.], mar. 1998. 